\title{
Physical activity and dietary behaviour in a population-based sample of British I0-year old children: the SPEEDY study (Sport, Physical activity and Eating behaviour: Environmental Determinants in Young people)
}

Esther MF van Sluijs*1, Paula ML Skidmore², Kim Mwanza², Andrew P Jones ${ }^{3}$, Alison M Callaghan ${ }^{1}$, Ulf Ekelund ${ }^{1}$, Flo Harrison ${ }^{3}$, Ian Harvey ${ }^{2}$, Jenna Panter ${ }^{3}$, Nicolas J Wareham ${ }^{1}$, Aedin Cassidy ${ }^{2}$ and Simon J Griffin ${ }^{1}$

Address: ${ }^{1}$ Medical Research Council Epidemiology Unit, Institute of Metabolic Science, Box 285, Addenbrookes Hospital, Hills Road, Cambridge, CB2 0QQ, UK, ${ }^{2}$ School of Medicine, Health Policy and Practice, University of East Anglia, Norwich, NR4 7JT, UK and ${ }^{3}$ School of Environmental Sciences, University of East Anglia, Norwich, NR4 7JT, UK

Email: Esther MF van Sluijs* - esther.vansluijs@mrc-epid.cam.ac.uk; Paula ML Skidmore - p.skidmore@uea.ac.uk; Kim Mwanza - kim.mwanza@nhs.net; Andrew P Jones - a.p.jones@uea.ac.uk; Alison M Callaghan - alison.callaghan@mrc-epid.cam.ac.uk; Ulf Ekelund - ulf.ekelund@mrc-epid.cam.ac.uk; Flo Harrison - flo.harrison@uea.ac.uk; Ian Harvey - ian.harvey@uea.ac.uk; Jenna Panter - j.panter@uea.ac.uk; Nicolas J Wareham - nick.wareham@mrc-epid.cam.ac.uk; Aedin Cassidy - a.cassidy@uea.ac.uk; Simon J Griffin - simon.griffin@mrc-epid.cam.ac.uk

* Corresponding author

Published: 14 November 2008

BMC Public Health 2008, 8:388 doi:10.1/86/147|-2458-8-388
Received: 9 June 2008

Accepted: 14 November 2008

This article is available from: http://www.biomedcentral.com//47/-2458/8/388

(C) 2008 van Sluijs et al; licensee BioMed Central Ltd.

This is an Open Access article distributed under the terms of the Creative Commons Attribution License (http://creativecommons.org/licenses/by/2.0), which permits unrestricted use, distribution, and reproduction in any medium, provided the original work is properly cited.

\begin{abstract}
Background: The SPEEDY study was set up to quantify levels of physical activity (PA) and dietary habits and the association with potential correlates in 9-10 year old British school children. We present here the analyses of the PA, dietary and anthropometry data.

Methods: In a cross-sectional study of 2064 children ( 926 boys, 1138 girls) in Norfolk, England, we collected anthropometry data at school using standardised procedures. Body mass index (BMI) was used to define obesity status. PA was assessed with the Actigraph accelerometer over 7 days. A cut-off of $\geq 2000$ activity counts was used to define minutes of moderate-to-vigorous PA (MVPA). Dietary habits were assessed using the Health Behaviour in School Children food questionnaire. Weight status was defined using published international cut-offs (Cole, 2000). Differences between groups were assessed using independent t-tests for continuous data and chisquared tests for categorical data.

Results: Valid PA data ( $>500$ minutes per day on $\geq 3$ days) was available for 1888 children. Mean $( \pm S D)$ activity counts per minute among boys and girls were $716.5 \pm 220.2$ and $635.6 \pm 210.6$, respectively $(\mathrm{p}<0.00 \mathrm{I})$. Boys spent an average of $84.1 \pm 25.9$ minutes in MVPA per day compared to $66.1 \pm 20.8$ among girls $(\mathrm{p}<0.00 \mathrm{I})$, with an average of $69.1 \%$ of children accumulating 60 minutes each day. The proportion of children classified as overweight and obese was $15.0 \%$ and $4.1 \%$ for boys and $19.3 \%$ and $6.6 \%$ for girls, respectively $(p=0.001$ ). Daily consumption of at least one
\end{abstract}


portion of fruit and of vegetables was $56.8 \%$ and $49.9 \%$ respectively, with higher daily consumption in girls than boys and in children from higher socioeconomic backgrounds.

Conclusion: Results indicate that almost $70 \%$ of children meet national PA guidelines, indicating that a prevention of decline, rather than increasing physical activity levels, might be an appropriate intervention target. Promotion of daily fruit and vegetable intake in this age group is also warranted, possibly focussing on children from lower socioeconomic backgrounds.

\section{Background}

A lack of physical activity and poor dietary habits are believed to be the major contributors to the current rise in childhood obesity [1-3]. Both behaviours have also been shown to have independent associations with other health problems during childhood, including metabolic impairments [4-8] and poor skeletal health [9,10]. They also tend to co-exist both in adults and children [11,12]. Increasing physical activity and improving dietary habits in childhood have therefore been identified as targets for future public health policy $[1,13]$. To be able to effectively promote changes in these complex health behaviours, reliable and valid data are needed about current patterns, and the demographic and modifiable factors that are most strongly associated with them. This will aid the identification of populations at risk and the development of interventions to promote change in these health behaviours.

To date, the extent of the problem of physical inactivity and unhealthy dietary habits in children is largely unknown. Descriptive data on patterns and levels of physical activity assessed using valid and reliable measures in large population-based samples is scarce, especially in children [14]. Previous studies have reported mixed results, with the proportion of children achieving the recommended guideline of at least one hour of moderate-tovigorous intensity physical activity (MVPA) each day [13] varying from 2.5 to $97 \%[13,15-18]$. This large variation mainly depends on the population studied and the variation in data processing methods applied. However, most studies indicate that physical activity levels decline with age, especially during late primary school years and throughout secondary school [19-21], making this a potentially important period for health promotion interventions. Although there is some information available on the nutritional content of the diet of primary schoolaged children (e.g. [22,23]), little is known about their dietary behaviour such as food choice. Previous studies either primarily focussed on secondary school-aged children [24] or were conducted a decade ago [25]. In order to develop behavioural interventions targeted at improving dietary habits and potentially prevent obesity in primary school-aged children, up-to-date information about the dietary habits is required.
The SPEEDY study (Sport, Physical activity and Eating behaviour: Environmental Determinants in Young people) was established to examine physical activity levels and dietary behaviour in a large population-based sample of British 9-10 year old children, and to investigate the individual and collective factors associated with these behaviours. The first aim of the SPEEDY study is to assess the extent of the problem of physical inactivity and unhealthy dietary habits. With its population-based sampling strategy, large sample size and detailed assessment of both physical activity and diet, the SPEEDY study will add to the existing evidence base. The aim of the current paper is to describe the SPEEDY study and the levels of physical activity and dietary habits of its participants.

\section{Methods \\ Study sample \\ School recruitment}

Schools in the county of Norfolk, South-East England, were sampled purposively to achieve heterogeneity in location. For logistical purposes, only schools with at least 12 Year 5 pupils (aged 9-10 years) were sampled. Head teachers at selected schools were first sent an invitation letter and an information leaflet, and then contacted to arrange a face-to-face visit. In this 10-minute visit, details were provided about the aims of the study, the invitation and measurement procedures, the degree of school involvement required, and potential benefits of participation. An information pack was provided at the visit, containing a copy of the ethical approval, examples of all study materials, and information leaflets for all Year 5 teachers. If they agreed that their school could take part, head teachers were asked to send the study team a signed acceptance letter. Upon request, a smaller sister school of one of the participating schools (a smaller school run under shared administration) was allowed to participate. School recruitment was completed prior to the start of data collection in April 2007.

\section{Participant recruitment}

Ethical approval for the SPEEDY study was obtained from the University of East Anglia local research ethics committee. Teams of two research assistants visited participating schools two weeks before the measurement date and introduced the SPEEDY study to all Year 5 children. Children were given an information pack containing a leaflet 
for themselves, a letter for their parents/guardians, and a consent form. Children were instructed to return the completed consent form to the school if they were willing to participate. A classroom poster was left at the school to remind the children of when the data collection was taking place. Three days before the measurement visit, a member of the research team contacted the school to assess response rates and to ask the class teacher to reinforce the message that children would not be able to participate without completed consent. Only children with a fully completed consent form (signed by both a parent/ guardian and the child) on the day of measurement were included in the study. An average of 168 children (range: 121 to 242 per week) was recruited into the study each week with an aim of recruiting 2000 children over a 12week period.

\section{Measurement procedures}

Data collection was performed during the Summer term of 2007 (April to July). Teams of two or more trained research assistants conducted measurements at participating schools according to standard operating procedures. They visited between five and 10 schools each week. All participating children self-completed their questionnaires with at least one research assistant available for assistance. Completeness of the questionnaire was determined onsite for quality control. Concurrently, research assistants measured anthropometry, obtained a saliva sample (children were asked to chew on a cotton swab) and explained the contents of the home pack (containing the 4-day food diary, Actigraph accelerometer and parent questionnaire). Children were instructed to return the home pack to school eight days after the measurement day for collection by a member of the study team. Class teachers distributed a reminder letter for parents two days before pack collection. Completion of packs was checked upon collection and follow-up of unreturned packs was conducted by the school administrative staff.

\section{Data collection and processing}

The descriptions below relate specifically to the measures for which data are presented in this paper.

\section{Aggregated school-level information}

Norfolk County Council provided school-based summary data on all Local Authority (state) schools. This included school status (state vs. private), postcode, number of Year 5 pupils, proportion of all children receiving free school meals, ethnicity distribution and participation in the Healthy Norfolk Schools Programme [26]. Also provided was data from the 2007 Norfolk Primary Care Trust Child Height and Weight Survey, containing information on anthropometry for over 85\% of Norfolk Year 6 children (aged 10-11 years). Data on independent private schools was provided by the Independent Schools Council or directly obtained from schools. Urban/rural classification for the schools was determined using Bibby and Shepherd's (2004) classification of rurality [27] and four density profiles, ranging from 'hamlet \& isolated dwelling' to 'urban, more than 10,000 inhabitants', were used in the present study.

\section{Demographic information}

Children self-reported their date of birth, and age was calculated using the measurement date. Ethnicity was reported separately by both parents using the UK standard classification. Results were combined to determine the child's ethnicity, which was collapsed into a dichotomous variable (white vs. other ethnic background). The parent or main carer self-reported their highest educational qualifications (in categories) and home postcode to determine urban/rural location.

\section{Anthropometry}

Simple non-invasive anthropometry measures were conducted using standardized procedures with children dressed in light clothing. Portable Leicester height measures were used to measure height to the nearest millimetre. Waist circumference was measured twice to the nearest millimetre at the midpoint between the lower costal margin and the level of the anterior superior iliac crests, using a Seca 200 measuring tape. A third measurement was taken if a discrepancy of three or more centimetres was observed and an average was calculated. A $0.5 \mathrm{~cm}$ correction was applied to account for clothing [28]. A non-segmental bio-impedance scale (Tanita, type TBF-300A) was used to measure weight (to the nearest 0.1 kilogram) and impedance. Previously validated and published equations were used to calculate body fat percentage (BF\%), fat mass (FM) and fat free mass (FFM) from the impedance value [29]. Body mass index (BMI) was calculated as weight (in kilograms) divided by height squared (in meters). Obesity status was determined using gender- and age-dependent cut points [30]. All scales were calibrated before and halfway through data collection. Quality assurance was established by assessing inter-observer variability of height and waist circumference before and after data collection, which was found to be acceptable (ranging from 0.1-0.3 centimetres for height and 0.7-1.3 centimetres for waist circumference).

\section{Physical activity}

Free-living physical activity was assessed over one week with the ActiGraph activity monitor (GT1M, Actigraph LCC, Pensacola, US). The children wore the accelerometer on an elastic waistband on the right hip during waking hours, except whilst bathing and during other aquatic activities. Children kept an Actigraph diary to report when they had taken the monitor off and for what reason. Activity data were stored at 5-second intervals and were down- 
loaded to a computer upon receipt. In case of monitor failure or lack of data, children were asked to re-wear the monitor for a further week. All monitors were calibrated using a mechanical spinner before the start of data collection. A bespoke programme (MAHUffe, http://www.mrcepid.cam.ac.uk) was used for data reduction and further analyses. The first day of data collection (day of measurement at school) was removed from all files and $10 \mathrm{~min}-$ utes of continuous zero counts were classified as 'non worn time'. The outcome variables were daily activity counts per minute (cpm) and time ( $\mathrm{min}$ ) spent in moderate to vigorous intensity physical activity (MVPA, $>2000$ (pm). This threshold corresponds to a walking pace of about $4 \mathrm{~km} / \mathrm{h}$ in children [31], and has been applied successfully in this age group before to study associations between physical activity intensity and metabolic outcomes [32]. Daily cpm is an indicator of the total volume of physical activity (i.e. average intensity of physical activity). This variable was derived by dividing total counts by monitoring time per day (between 6.00 and 23.00) and averaged over the measurement period. We have previously shown that this variable is significantly correlated with physical activity energy expenditure obtained by the doubly-labelled water method [33]. Children who did not manage to record valid data for at least 500 minutes per day on at least 3 days were excluded from further analyses.

\section{Dietary behaviour}

Food choice was assessed using an adapted version of the Health Behaviour in School Children (HBSC) questionnaire, a 15 -item questionnaire of the most commonly consumed foods that has been previously validated in a Belgian sample and can be used for ranking participants for most food items [34]. Adaptations to the items included removing alcohol consumption, adding fruit juice consumption and separating sweets and chocolate into two separate items. Children reported on the frequency of consumption on a 7-point scale. Results were dichotomized at less than once per day ("never", "less than once per week", "once per week", "2-4 days per week", "5-6 days per week") vs. once or more per day ("once a day, every day", "every day, more than once") [35].

\section{Statistical analyses}

Descriptive data were summarized as means with standard deviations or percentages, and differences between groups were tested using independent samples t-tests or Pearson Chi-square tests. Differences between activity levels on week- and weekend days were tested using paired ttests, and Chi-square tests were used to test for differences between groups meeting the physical activity guideline or consuming at least one portion of fruit and vegetable per day.

\section{Results \\ Recruitment}

Figure 1 provides an overview of recruitment of schools and children. A total of 227 (214 state and 13 independent) schools were eligible for recruitment, of which 157 were sent an invitation letter. 101 Schools agreed to participate in the SPEEDY study and measurements sessions were conducted at 92 schools (58.6\% of invited schools). At these 92 schools, 3619 Year 5 children were invited to take part (range per school: 5-155), measurements were performed on a total of 2064 children $(57.0 \%$ of eligible sample) with response rates per school ranging from $13 \%$ to $100 \%$. Of these, a total of 2043 children returned the Actigraph accelerometer (99.0\%), with 1868 (90.5\%) providing valid data. No differences were observed between children with and without valid physical activity data for BMI, overweight status, or parental education. However, girls were more likely to not provide valid data.

\section{Sample description}

Table 1 provides an overview of the characteristics of participating schools. Compared with all eligible Norfolk schools, village schools were over-sampled in the SPEEDY study, with an under-sampling of schools in urban areas and of independent schools. Table 2 provides a description of characteristics of the SPEEDY children. A higher proportion of girls than boys participated and only a small proportion of children were from a non-white ethnic background.

\section{Anthropometry}

Table 2 describes the anthropometric data collected in the SPEEDY study. Compared with boys, girls were heavier, had less fat free mass and more fat mass, a higher body fat percentage and a higher BMI (all $\mathrm{p}<0.001$ ). In addition, a higher proportion of girls than boys were classified as either overweight or obese.

\section{Physical activity}

Table 3 describes the data on objectively measured physical activity stratified by gender. Overall physical activity and time (min/day) spent in MVPA was significantly higher $(\mathrm{p}<0.001)$ in boys than girls. Both boys and girls did more activity overall on weekend days compared with weekdays. However, time spent at moderate and vigorous intensity activity did not differ between weekend and weekdays in either gender. Figure 2 shows that a higher proportion of boys than girls met the physical activity guideline, and that the proportion differs by weight status and home location

\section{Dietary behaviour}

Table 4 shows the results of the food choice questionnaire. Daily consumption of fruit and of vegetables was $56.8 \%$ and $49.9 \%$ respectively, with girls reporting daily 
55 schools excluded

Reason: less than 12 Year 5 pupils on role

$\downarrow$

227 eligible schools

70 schools not sampled

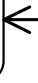

$\downarrow$

157 schools sampled to be approached (via post and telephone follow up)

65 schools did not take part

Reasons: refused visit $(N=20)$; unavailable for visit

$(N=33)$; refused after visit $(N=4)$; waiting list $(N=8$
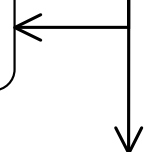

92 schools visited for measurements (58.6\%)

3619 available Year 5 pupils invited

1552 children did not participate

Reasons: not available on day $(\mathrm{N}=64)$; declined $(\mathrm{N}=282)$; consent not returned $(\mathrm{N}=1206)$

3 children withdrew after measurements

2067 year 5 children consented and participated in measurements $(57.1 \%)$

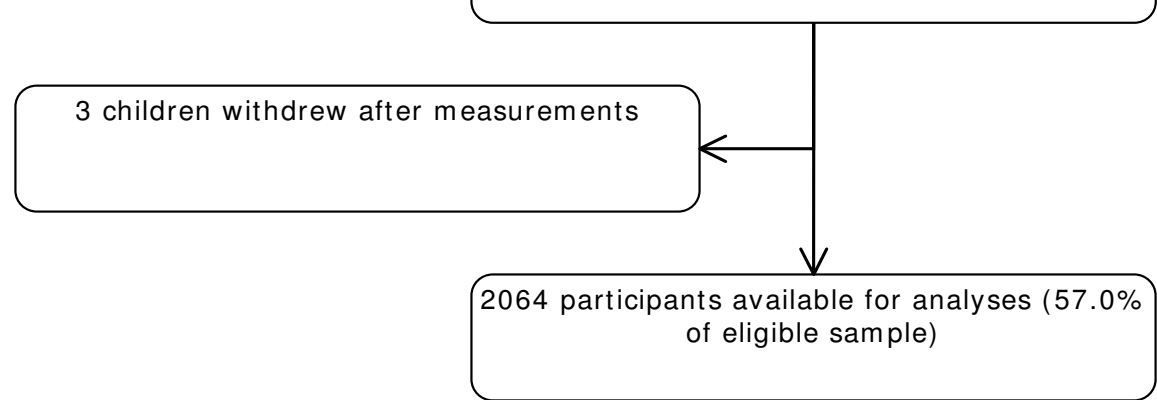

Figure I

Flowchart of recruitment of schools and children into the SPEEDY study. 
Table I: Characteristics of the schools participating in SPEEDY study compared with available data on eligible Norfolk schools.

\begin{tabular}{lll}
\hline & SPEED schools & All eligible Norfolk schools \\
\hline School location & & $34.7 \%$ \\
- Urban ( 10,000 inhabitants) & $32.6 \%$ & $38.0 \%$ \\
- Town and fringe & $39.1 \%$ & $20.7 \%$ \\
- Village & $23.9 \%$ & $6.6 \%$ \\
- Hamlet \& isolated dwelling & $4.3 \%$ & $7.5 \%$ \\
\hline Independent school & $3.3 \%$ & $9.0 \%$ \\
\hline Free school meals (\% children) (median) & $9.0 \%$ & $42.6 \%$ \\
\hline Norfolk Healthy Schools participation (\%) & $38.2 \%$ & $4.6 \%$ \\
\hline Ethnicity (\% non-British White) (median) & $5.2 \%$ & \\
\hline Weight status (\%)* & & $13.8 \%$ \\
- overweight & $13.4 \%$ & $15.8 \%$ \\
\hline obese & $16.7 \%$ & 31 \\
\hline No of year 5 pupils (median) & 31 & $51.0 \%$ \\
\hline Sex (\% boys in Year 6) & $52.5 \%$ & \\
\hline
\end{tabular}

NOTE: Figures based on data aggregated at school level. Data on Healthy Norfolk Participation, ethnicity, BMl and sex were only available for state schools, \%Free school meals not applicable for independent schools.

*: assessed in Summer 2007 in Year 6 children (Norfolk Primary Care Trust child Height and Weight Survey).

consumption more frequently than boys. $41.3 \%$ of children reported eating at least one piece of fruit and one serving of vegetables per day, with significant differences between sexes (see Figure 2). This percentage also increased with increasing socioeconomic status, but did not differ by weight status or home location. It was also not associated with meeting physical activity guidelines ( $40.7 \%$ vs. $42.2 \%$ for whether or not participants were meeting the physical activity guideline, respectively). More than half of children reported daily consumption of skimmed or semi-skimmed milk, breakfast cereals and fruit juices.

\section{Discussion}

The aim of the current paper was to present data on physical activity and dietary behaviour from a populationbased sample of British 9-10 year old children. Results showed that more than two-thirds of children adhere to the physical activity guideline of accumulating at least 60 minutes of MVPA each day, but that daily consumption of fruit or of vegetables was only reported by $56.8 \%$ and $49.9 \%$ of the children. Boys were more likely to be physically active and of normal weight than girls. In contrast, boys' reported daily consumption of 'healthy' foods was lower, and their consumption of snacks and unhealthy food items such as soft drinks was higher than that of girls. In addition, normal weight children were more likely to meet physical activity guidelines than overweight and obese children, whereas children from a higher socioeconomic background were more likely to eat fruit and vegetable daily.

\section{Physical activity}

Estimates of total physical activity, represented as average counts per minute, are largely comparable to the results of previous population-based studies in a similar age group in Britain and other European countries $[15,16,36,37]$. The small differences observed may be due to differences in monitors used and data processing strategies. However, it may also be due to the known age-related decline in physical activity $[16,19]$, potential decreases in physical activity levels in the past decade $[15,37]$, or seasonal effects $[15,16,36]$. As consistently reported before $[15,16,19]$, boys were substantially more active than girls. In contrast to previous work, the data in this study were collected only during the spring and early summer. A seasonal effect on physical activity levels in children has previously been established $[16,38,39]$, with lower activity levels observed during cold or extreme weather. Therefore, our estimate of overall physical activity may be overestimated compared with studies collecting data throughout the year. The timing of our measurements may also explain the observation that children were consistently more active on weekend days than on weekdays, in contrast to previous work $[16,40]$. During European spring and summer, children will be more likely to play outside 
Table 2: Descriptive personal and anthropometry data on the SPEEDY study sample (all numbers in cells are mean (standard deviation) unless stated otherwise)

\begin{tabular}{|c|c|c|c|}
\hline & Boys & Girls & Total \\
\hline$N(\%)$ & $926(44.9)$ & II $38(55.1)$ & 2064 \\
\hline Age (years) & $10.2(0.3)$ & $10.3(0.3)$ & $10.3(0.3)$ \\
\hline Ethnicity (\% non-white) & 3.8 & 3.8 & 3.8 \\
\hline \multicolumn{4}{|l|}{ SES - parental education (\%) } \\
\hline - GCSE or lower & 36.3 & 40.6 & 38.7 \\
\hline - up to $\mathrm{A}$ level & 42.2 & 40.4 & 41.2 \\
\hline - higher education & 21.4 & 18.9 & 20.0 \\
\hline \multicolumn{4}{|l|}{ Home location } \\
\hline - Urban (>10,000 inhabitants) & 40.3 & 38.9 & 39.6 \\
\hline - Town and fringe & 26.6 & 29.9 & 28.4 \\
\hline - Village & 25.4 & 24.7 & 25.0 \\
\hline - Hamlet \& isolated dwelling & 7.7 & 6.5 & 7.0 \\
\hline Height $(\mathrm{cm})$ & $140.9(6.5)$ & $141.0(6.8)$ & $141.0(6.7)$ \\
\hline Weight $(\mathrm{kg})$ & $35.7(7.7)$ & $37.1(8.8) *$ & $36.5(8.4)$ \\
\hline Bodyfat $\%$ & $27.2(7.5)$ & $33.2(7.3)^{*}$ & $30.5(7.9)$ \\
\hline Waist circumference $(\mathrm{cm})$ & $63.6(7.8)$ & $63.6(9.0)$ & $63.6(8.4)$ \\
\hline BMI (kg/m2) & $17.9(2.9)$ & $18.5(3.4)^{*}$ & $18.2(3.2)$ \\
\hline \multicolumn{4}{|l|}{ Weight status (\%) } \\
\hline - overweight & 15.0 & $19.3^{*}$ & 17.4 \\
\hline - obese & 4.1 & 6.6 & 5.5 \\
\hline
\end{tabular}

*Statistical significant difference between boys and girls at $p \leq 0.00$ I for longer periods of time in their free time as a result of comfortable temperatures and longer hours of daylight. Time spent outside has previously been associated with higher activity levels [19].

In contrast to total activity levels, estimates of time spent in at least moderate-to-vigorous physical activity and of proportions of children meeting guidelines differ from other studies. Previous estimates of minutes of MVPA per day in this age group range from 20 to 192 minutes per day, with 2.5 to $97 \%$ achieving the recommended guideline of at least 60 minutes of MVPA each day of the week $[13,15-18]$. On average, the children in the SPEEDY study accumulated 74.1 minutes of MVPA per day, with $69.1 \%$ of children being classified as sufficiently active according to current physical activity recommendations. This value is higher compared with previous estimates in British children recently reported [16]. However, data on time spent at MVPA and prevalence of children being sufficiently active according to recommendations are not directly comparable between studies. This is explained by different thresholds used when defining MVPA, for which currently no consensus exists. Previously published thresholds for MVPA vary substantially depending on the activities performed during the calibration process, and the choice of intensity threshold will affect the results for MVPA substantially. This at least in part explains the discrepancy with previously published British data [16], where the authors used a threshold of $3600 \mathrm{cpm}$, a substantially higher threshold than used in previous work $[15,17]$ and in the current study. This threshold $(2000$ $\mathrm{cpm})$, however, lies mid-way between the various intensity thresholds derived in children, which range from 615 [41] to 3600 counts per minute [16].

One interpretation of our data could be that only one third of children at this age are insufficiently active. However, this interpretation may be dangerous as recent data

Table 3: Description of physical activity variables as collected with Actigraph accelerometers in the SPEEDY study.

\begin{tabular}{llll}
\hline & Boys (N = 822) & Girls (N = 1 046) & Total (N = I 868) \\
\hline $\begin{array}{l}\text { Counts per minute } \\
\text { - Weekday }\end{array}$ & $682.6(176.9)$ & & $632.4(175.3)$ \\
- Weekend day & $754.8(346.9)^{\#}$ & $592.9(163.5)^{*}$ & $719.6(346.7)^{\#}$ \\
- Total week & $716.5(220.2)$ & $690.7(343.9)^{*} \#$ & $671.2(218.6)$ \\
\hline Minutes of MVPA & $635.6(210.6)^{*}$ & $73.5(23.1)$ \\
- Weekday & $83.5(23.4)$ & & $75.3(35.3)$ \\
- Weekend day & $85.1(38.5)$ & $65.5(19.5)^{*}$ & $74.1(24.9)$ \\
- Total week & $84.1(25.9)$ & $67.2(30.2)^{*}$ & $66.1(20.8)^{*}$ \\
\hline
\end{tabular}

Differences between boys and girls tested with independent $\mathrm{t}$-tests, differences between week and weekend day activity with paired samples t-tests.

*: difference between boys and girls at $\mathrm{P}<0.001$.

\#: difference between weekday and weekend day activity within group at $p<0.00$ I 
A.

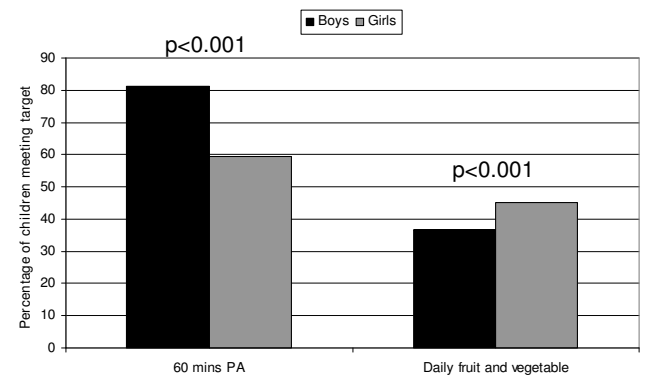

B.

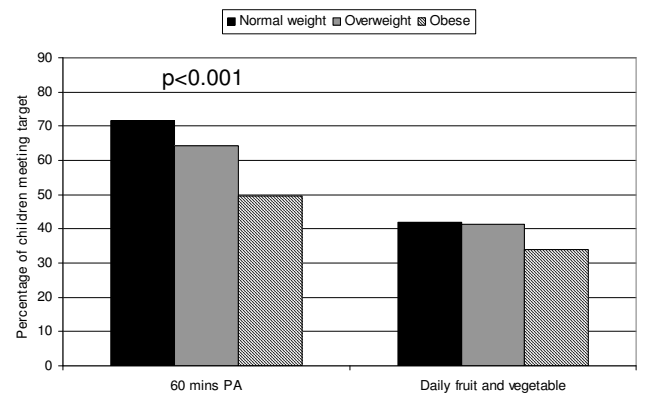

C.

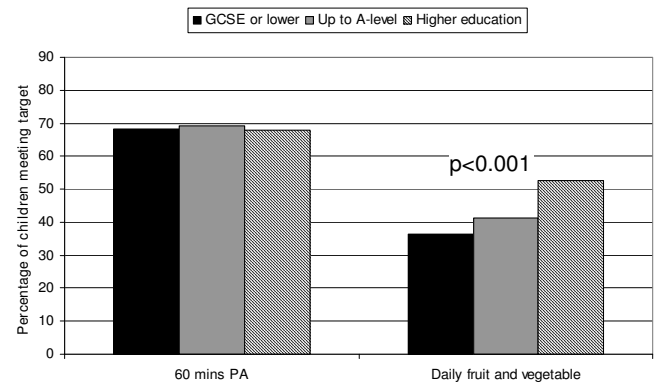

D.

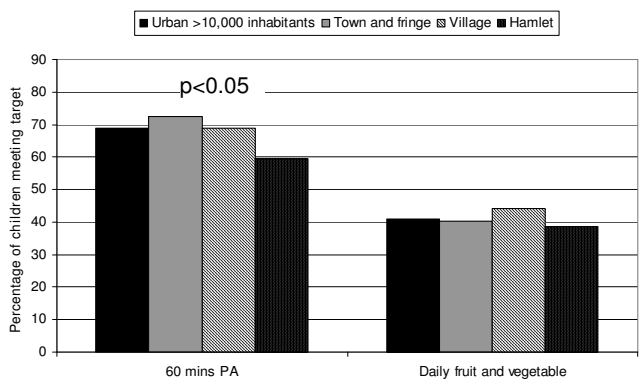

Figure 2

Percentage of SPEEDY children meeting physical activity (PA) guideline of 60 minutes per day on an average day of the week and reporting consuming at least one piece of fruit and one serving of vegetable per day, stratified by demographic characteristics (A. sex; B. weight status; C. parental education (indicator of socioeconomic status); and D. home location). 
Table 4: Dietary habits of the SPEEDY sample, as measured with food frequency questionnaire (numbers in cells are percentage of children reporting to consume the food type at least once a day)

\begin{tabular}{|c|c|c|c|}
\hline & Boys & Girls & Total \\
\hline Fruit & 51.6 & $61.1 *$ & 56.8 \\
\hline Vegetables & 44.8 & $54.1^{*}$ & 49.9 \\
\hline Sweets & 18.4 & $12 . I^{*}$ & 14.9 \\
\hline Chocolate & 18.6 & $14.2^{*}$ & 16.2 \\
\hline Sugary soft drinks (e.g. coke) & 16.1 & $9.3^{*}$ & 12.4 \\
\hline Diet soft drinks & 16.2 & $11.7^{*}$ & 13.8 \\
\hline Skimmed/semi-skimmed milk & 54.1 & 51.0 & 52.4 \\
\hline Whole fat milk & 15.6 & 13.2 & 14.3 \\
\hline Cheese & 17.4 & 16.4 & 16.9 \\
\hline Breakfast cereals & 60.1 & $51.9 *$ & 55.6 \\
\hline White bread & 44.0 & 41.7 & 42.7 \\
\hline Brown bread & 22.3 & 20.0 & 21.0 \\
\hline Crisps & 24.1 & 20.5 & 22.1 \\
\hline Chips & 7.8 & $5.3^{*}$ & 6.4 \\
\hline Fruit juices & 54.5 & 54.9 & 54.7 \\
\hline
\end{tabular}

Differences between boys and girls tested with Pearson Chi-square.

$*$ : differences between boys and girls at $p<0.05$

suggest that about 90 to 120 minutes of moderate intensity physical activity is needed to prevent clustering of cardiovascular risk factors in children [6]. Given the wellestablished age-related decline in physical activity which appears to start before puberty $[20,21]$, examining the correlates and determinants of physical activity and of changes in physical activity is therefore of particular interest in this age group in order to inform preventive action. Such interventions may be better placed if they focus on preventing declines in physical activity, and not necessarily increases in physical activity.

\section{Diet}

A pattern of unhealthy food choices was revealed with high consumption of energy and fat dense food and refined carbohydrates. Our results however compare favourably to those from a previously reported HBSC survey in a slightly older population (11-15 year olds) in 35 countries. Here daily fruit and vegetable consumption ranged between $20-50 \%$ and $10-50 \%$, respectively [24]. Results from 6081 participating English adolescents indicated that only $25 \%$ reported daily fruit consumption, with daily vegetable consumption just under $30 \%$. In addition, about $40 \%$ of adolescents reported daily consumption of soft drinks, compared with $12 \%$ in the SPEEDY population. Whether these differences are due to age-related decline in healthy dietary habits, changes over time (the HSBC data was collected in 2002), reporting bias, or differences in populations studied, remains uncertain.

Results of the current study are largely in agreement with results from the National Diet and Nutrition Survey (NDNS) in children aged 7 to 10 years, conducted in 1997 [25]. In this study, for example, consumption of semi- and skimmed milk and white bread was also higher than whole milk and brown or wholemeal bread. Moreover, boys were less likely to regularly consume vegetables, whereas girls consumed less breakfast cereals than boys. In contrast, the children in the SPEEDY study reported a higher consumption of both artificially sweetened and sugary soft drinks, which may reflect changes in children's food consumption over time.

It is known that children's recall of food intake is prone to reporting errors $[42,43]$ and that children's interest and enthusiasm may wane during lengthy dietary assessment periods. Therefore the short HBSC questionnaire was used to assess intake of the most commonly consumed foods rather than exact intake of nutrients, in order to collate information on trends in dietary intake. Under-reporting of energy intake has previously been reported in both boys and girls $[44,45]$, with under-reporters reporting consuming the same number of fruit and vegetable servings, but fewer servings from sweets and fats groups [44]. Under-reporting is also associated with weight status [46], possibly explaining the observed healthier dietary profile in girls compared to boys given the differences in weight status by gender. As with the physical activity measurement, it is likely that seasonal influences have played a role in the assessment of dietary intake [47]. In particular fruit and vegetable availability and choice of food and drink consumption in warmer weather might have increased the reported consumption frequency of fruit, vegetables and soft drinks.

\section{Recruitment and representativeness}

One of the aims of the sampling strategy in the SPEEDY study was to achieve maximum environmental heterogeneity in order to address questions relating to environmental influences on behaviour. In line with this we recruited a larger proportion of schools in rural than in urban locations. This might have affected the prevalence 
of certain behaviours amongst our school sample, and hence their representativeness to the wider population. On the other hand, as the other characteristics of the sampled schools are comparable to those of all eligible schools, it appears that we recruited a broadly representative sample of schools into our study.

Of all invited children, $57.0 \%$ took part in the data collection. Response rates may have been affected by the amount of data collected, the speed of the data collection (leaving ample time for additional reminder efforts), the recruitment method (only contact with children through schools) and previous negative research experiences in schools. No data is available on those children not taking part, reducing the potential to establish the representitaveness of the study sample. It does appear that girls are overrepresented in the study and, compared to the Norfolk population, that a smaller proportion of obese children have taken part. Data using school-based assessments of obesity levels in Year 6 children across Norfolk in the same year indicate that $14.1 \%$ are classified as overweight and $15.8 \%$ obese [48]. It is well-established that nonresponders to health surveys are more likely to have an unhealthy lifestyle, and this may have resulted in more positive prevalence estimates. Our final sample is mainly white with only $3.8 \%$ of children from other ethnic backgrounds. Although this is representative of the Norfolk population, it also reduces the generalizability of our results to the wider British population.

\section{Strengths and limitations of the SPEEDY study}

Strengths of the SPEEDY study include the populationbased sampling strategy, the large sample size, the use of objective and valid measures of physical activity and anthromopometry and of a frequently used and validated food frequency questionnaire. An intensive measurement period meant that measurements were only conducted during the Summer term. The advantage of this approach is the reduced influence of weather on the physical activity measurements and its potential confounding effect on the association with potential correlates. However, it may have affected the absolute levels of physical activity and diet intake presented. Other limitations include the use of a self-report measure of dietary intake, a suspected higher non-response of obese children and the fact that the demographic profile of the county of Norfolk is not representative for the whole of Britain.

The second aim of the SPEEDY study is to examine individual and collective factors associated with physical activity levels and dietary behaviour in a large populationbased sample of British 9-10 year old children. The study is the first European study in children setting out to collect objectively measured physical activity and detailed dietary information together with a wide range of potential corre- lates from the psychological, biological, socio-cultural and environmental domains [49]. Future studies from the SPEEDY study will address these associations and provide much-needed information on where and how to target intervention efforts most effectively [50] in order to improve physical activity and dietary behaviours in children.

\section{Conclusion}

The aim of the current paper was to provide descriptive data on physical activity and dietary behaviour of the children participating in the SPEEDY study. The results show that physical activity levels are relatively high, especially in boys, indicating that a prevention of decline, rather than increasing physical activity levels, might be a modifiable focus for intervention development in this age group. Although the dietary habits of the SPEEDY children seems to be better than reported in previous studies, a significant proportion of the children reported consuming limited intakes of fruit and vegetables. Therefore, promotion of daily fruit and vegetable intake in this age group is warranted, possibly focussing on children from lower socioeconomic backgrounds.

\section{Competing interests}

The authors declare that they have no competing interests.

\section{Authors' contributions}

EvS, PS, AJ, AC and SG were responsible for conception of the study, study design, set up and data collection and processing. KM coordinated the data collection. AMC, FH and JP participated in the data collection and processing. $\mathrm{IH}$, UE and NW were involved with conception of the study and study design. EvS analyzed the data and drafted the manuscript. All authors were involved with data interpretation, critical revisions of the paper and provided approval for its publication.

\section{Acknowledgements}

We would like to thank the schools, the children and their parents for their participation in the SPEEDY study. We also thank everyone who helped with the data collection and Norfolk County Council Children's Services for their invaluable input and support. We also thank the HBSC International Coordinating Centre for allowing us to use the HBSC dietary questionnaire.

EvS, UE, NW and SG are funded by the Medical Research Council (MRC). PS, APJ, IH and AC are funded by the Higher Education Funding Council for England (HEFCE). AMC is funded by a University of Cambridge studentship. $\mathrm{FH}$ is funded by an ESRC/MRC interdisciplinary research studentship. The SPEEDY study is funded by the National Prevention Research Initiative http://www.npri.org.uk, consisting of the following Funding Partners: British Heart Foundation; Cancer Research UK; Department of Health; Diabetes UK; Economic and Social Research Council; Medical Research Council; Research and Development Office for the Northern Ireland Health and Social Services; Chief Scientist Office, Scottish Executive Health Department; Welsh Assembly Government and World Cancer Research Fund. 
KM and JP are funded from this grant. None of the funders had a role in study design, writing of the manuscript or the decision to submit this paper to BMC Public Health.

\section{References}

I. Butland B, Jebb SA, Kopelman P, McPherson K, Thomas S, Mardell J, Parry V: Foresight. Tackling obesities: future choices - project report. London, UK: Government Office for Science; 2007.

2. Lobstein T, Baur L, Uauy R: Obesity in children and young people: a crisis in public health. Obes Rev 2004, 5(Suppl I):4-I04.

3. Krebs NF, Jacobson MS: Prevention of pediatric overweight and obesity. Pediatrics 2003, I I 2(2):424-430.

4. Ekelund U, Anderssen SA, Froberg K, Sardinha LB, Andersen LB, Brage $S$ : Independent associations of physical activity and cardiorespiratory fitness with metabolic risk factors in children the European youth heart study. Diabetologia 2007 50(9): $1832-1840$.

5. Imperatore G, Cheng YJ, Williams DE, Fulton J, Gregg EW: Physical activity, cardiovascular fitness, and insulin sensitivity among U.S. adolescents: the National Health and Nutrition Examination Survey, 1999-2002. Diabetes Care 2006, 29(7): I567-1572.

6. Andersen LB, Harro M, Sardinha LB, Froberg K, Ekelund U, Brage S, Anderssen SA: Physical activity and clustered cardiovascular risk in children: a cross-sectional study (The European Youth Heart Study). Lancet 2006, 368(9532):299-304.

7. Garemo M, Palsdottir V, Strandvik B: Metabolic markers in relation to nutrition and growth in healthy 4-y-old children in Sweden. Am J Clin Nutr 2006, 84(5): I02I-1026.

8. Williams CL, Strobino BA: Childhood diet, overweight, and CVD risk factors: the Healthy Start project. Preventive cardiology 2008, I I (I): I I-20.

9. Hind $\mathrm{K}$, Burrows $\mathrm{M}$ : Weight-bearing exercise and bone mineral accrual in children and adolescents: a review of controlled trials. Bone 2007, 40(I): | 4-27.

10. Prentice A, Schoenmakers I, Laskey MA, de Bono S, Ginty F, Goldberg GR: Nutrition and bone growth and development. Proc Nutr Soc 2006, 65(4):348-360.

II. Ekelund U, Brage S, Froberg K, Harro M, Anderssen SA, Sardinha LB, Riddoch $C$, Andersen $L B$ : TV viewing and physical activity are independently associated with metabolic risk in children: the European Youth Heart Study. PLoS Med 2006, 3(I 2):e488.

12. Rennie KL, Johnson L, Jebb SA: Behavioural determinants of obesity. Best practice \& research 2005, I 9(3):343-358.

13. Department of Health: At least five a week: evidence on the impact of physical activity and its relationship to health. London: Department of Health; 2004

14. Wareham NJ, van Sluijs EM, Ekelund U: Physical activity and obesity prevention: a review of the current evidence. Proc Nutr Soc 2005, 64(2):229-247.

I5. Riddoch C], Bo Andersen L, Wedderkopp N, Harro M, KlassonHeggebo L, Sardinha LB, Cooper AR, Ekelund U: Physical activity levels and patterns of 9- and I5-yr-old European children. Med Sci Sports Exerc 2004, 36(I):86-92.

16. Riddoch CJ, Mattocks C, Deere K, Saunders J, Kirkby J, Tilling K Leary SD, Blair S, Ness A: Objective measurement of levels and patterns of physical activity. Arch Dis Child 2007, 92:963-969.

17. Pate RR, Freedson PS, Sallis JF, Taylor WC, Sirard J, Trost SG, Dowda $M$ : Compliance with physical activity guidelines: prevalence in a population of children and youth. Ann Epidemiol 2002 I 2(5):303-308.

18. Spinks AB, Macpherson AK, Bain C, McClure RJ: Compliance with the Australian national physical activity guidelines for children: Relationship to overweight status. Journal of Science and Medicine in Sport 2007, I0(3): I56-163.

19. Sallis JF, Prochaska J], Taylor WC: A review of correlates of physical activity of children and adolescents. Med Sci Sports Exerc 2000, 32(5):963-975.

20. Sherar LB, Esliger DW, Baxter-Jones AD, Tremblay MS: Age and gender differences in youth physical activity: does physical maturity matter? Med Sci Sports Exerc 2007, 39(5):830-835

21. Kimm SY, Glynn NW, Kriska AM, Barton BA, Kronsberg SS, Daniels $\mathrm{SR}$, Crawford PB, Sabry ZI, Liu K: Decline in physical activity in black girls and white girls during adolescence. $N \mathrm{Engl}] \mathrm{Med}$ 2002, 347(I 0):709-7I5.
22. Glynn L, Emmett P, Rogers I: Food and nutrient intakes of a population sample of 7-year-old children in the south-west of England in 1999/2000 - what difference does gender make? Hum Nutr Diet 2005, I 8(I):7-19. quiz 21-13

23. Rugg-Gunn AJ, Adamson AJ, Appleton DR, Butler TJ, Hackett AF: Sugars consumption by 379 I I-I2-year-old English children in 1990 compared with results in 1980. J Hum Nutr Diet 2007. 20(3): $171-183$

24. Vereecken CA, De Henauw S, Maes L: Adolescents' food habits: results of the Health Behaviour in School-aged Children survey. The British journal of nutrition 2005, 94(3):423-43I.

25. Gregory J, Lowe S: National Diet and Nutrition Survey: Young People Aged 4 to 18 Years. Report of the Diet and Nutrition Survey. Volume I. London: The Stationary Office; 2000.

26. Healthy Norfolk Schools [http://schools.norfolk.gov.uk/mypor tal/index.cfm? $=|\& m=| 326 \& p=9 \mid 2$,index]

27. Bibby $\mathrm{P}$, Shepherd J: Developing a new classification of urban and rural areas for policy purposes - the methods. London: RERC, School of Town and Regional Planning, University of Sheffield and Birkbeck College, University of London; 2004.

28. McCarthy HD, Ellis SM, Cole TJ: Central overweight and obesity in British youth aged I I- 16 years: cross sectional surveys of waist circumference. BM/ 2003, 326(7390):624.

29. Tyrrell VJ, Richards G, Hofman P, Gillies GF, Robinson E, Cutfield WS: Foot-to-foot bioelectrical impedance analysis: a valuable tool for the measurement of body composition in children. Int J Obes Relat Metab Disord 200I, 25(2):273-278.

30. Cole TJ, Bellizzi MC, Flegal KM, Dietz WH: Establishing a standard definition for child overweight and obesity worldwide: international survey. Bmj 2000, 320(7244): I 240-I 243.

31. Trost SG, Ward DS, Moorehead SM, Watson PD, Riner W, Burke JR: Validity of the computer science and applications (CSA) activity monitor in children. Med Sci Sports Exerc 1998, 30(4):629-633

32. Ekelund U, Sardinha LB, Anderssen SA, Harro M, Franks PW, Brage S, Cooper AR, Andersen LB, Riddoch C, Froberg K: Associations between objectively assessed physical activity and indicators of body fatness in 9- to 10 -y-old European children: a population-based study from 4 distinct regions in Europe (the European Youth Heart Study). Am J Clin Nutr 2004, 80(3):584-590.

33. Ekelund U, Sjostrom M, Yngve A, Poortvliet E, Nilsson A, Froberg K, Wedderkopp N, Westerterp K: Physical activity assessed by activity monitor and doubly labeled water in children. Med Sci Sports Exerc 200I, 33(2):275-28I.

34. Vereecken CA, Maes L: A Belgian study on the reliability and relative validity of the Health Behaviour in School-Aged Children food-frequency questionnaire. Public Health Nutr 2003. 6(6):58|-588.

35. Vereecken CA, Inchley J, Subramanian SV, Hublet A, Maes L: The relative influence of individual and contextual socio-economic status on consumption of fruit and soft drinks among adolescents in Europe. Eur J Public Health 2005, I 5:224-232.

36. Rowlands AV, Pilgrim EL, Eston RG: Patterns of habitual activity across weekdays and weekend days in 9-II-year-old children. Prev Med 2008, 46(4):317-324.

37. Page A, Cooper AR, Stamatakis E, Foster LI, Crowne EC, Sabin M, Shield JP: Physical activity patterns in nonobese and obese children assessed using minute-by-minute accelerometry. Int J Obes Relat Metab Disord 2005, 29(9): I070-1076.

38. Fisher A, Reilly JJ, Montgomery C, Kelly LA, Williamson A, Jackson DM, Paton JY, Grant S: Sesonality in physical activity and sedentary behaviour in young children. Ped Excercise Science 2005 I 7:31-40.

39. Tucker P, Gilliland J: The effect of season and weather on physical activity: a systematic review. Public Health 2007, I 2 I ( I 2):909-922

40. Rowlands AV, Pilgrim EL, Eston RG: Patterns of habitual activity across weekdays and weekend days in 9-II-year-old children. Preventive Medicine 2008, 46(4):317-324.

4I. Metallinos-Katsaras ES, Freedson PS, Fulton JE, Sherry B: The association between an objective measure of physical activity and weight status in preschoolers. Obesity (Silver Spring, Md) 2007, I 5(3):686-694.

42. Domel SB: Self-reports of diet: how children remember what they have eaten. Am / Clin Nutr 1997, 65(4 Suppl): I I48S-I I 52S. 
43. Crawford PB, Obarzanek E, Morrison J, Sabry ZI: Comparative advantage of 3-day food records over 24-hour recall and 5day food frequency validated by observation of 9- and 10year-old girls. J Am Diet Assoc 1994, 94(6):626-630.

44. Ventura AK, Loken E, Mitchell DC, Smiciklas-Wright H, Birch LL: Understanding reporting bias in the dietary recall data of IIyear-old girls. Obesity (Silver Spring, Md) 2006, I4(6): 1073-1084.

45. Lillegaard IT, Andersen LF: Validation of a pre-coded food diary with energy expenditure, comparison of under-reporters $v$. acceptable reporters. The British journal of nutrition 2005, 94(6):998-1003.

46. Livingstone MB, Robson PJ, Wallace JM: Issues in dietary intake assessment of children and adolescents. The British journal of nutrition 2004, 92(Suppl 2):S2 I 3-222.

47. Givens ML, Lu C, Bartell SM, Pearson MA: Estimating dietary consumption patterns among children: a comparison between cross-sectional and longitudinal study designs. Environmental research 2007, 103(3):325-330.

48. National Child Measurement Programme 2006/07 [http:// www.nemp.ic.nhs.uk/]

49. Kohl HW 3rd, Hobbs KE: Development of physical activity behaviors among children and adolescents. Pediatrics 1998, I 01 (3 Pt 2):549-554.

50. Ball K, Timperio AF, Crawford DA: Understanding environmental influences on nutrition and physical activity behaviors: where should we look and what should we count? Int J Behav Nutr Phys Act 2006, 3:33.

\section{Pre-publication history}

The pre-publication history for this paper can be accessed here:

http://www.biomedcentral.com/1471-2458/8/388/pre pub

Publish with Bio Med Central and every scientist can read your work free of charge

"BioMed Central will be the most significant development for disseminating the results of biomedical research in our lifetime."

Sir Paul Nurse, Cancer Research UK

Your research papers will be:

- available free of charge to the entire biomedical community

- peer reviewed and published immediately upon acceptance

- cited in PubMed and archived on PubMed Central

- yours - you keep the copyright

Submit your manuscript here:

http://www.biomedcentral.com/info/publishing_adv.asp
BiolMedcentral 